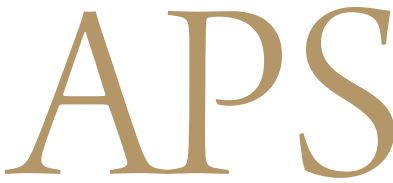

Archives of Plastic Surgery

\title{
Semicircular Horizontal Approach in Breast Reduction: Clinical Experience in 38 Cases
}

\author{
Hee Su Shin, Yong Hae Lee, Sung Gyun Jung, Doo Hyung Lee, Young Roe, Jong Hyun Cha \\ Department of Plastic and Reconstructive Surgery, Konyang University College of Medicine, Daejeon, Korea
}

Background Various techniques are used for performing breast reduction. Wise-pattern and vertical scar techniques are the most commonly employed approaches. However, a vertical scar in the mid-lower breast is prominent and aesthetically less pleasant. In contrast, a semicircular horizontal approach does not leave a vertical scar in the mid breast and transverse scars can be hidden in the inframammary fold. In this paper, we describe the experiences and results of semicircular horizontal breast reductions performed by a single surgeon.

Methods Between September 1996 and October 2013, our senior author used this technique in 38 cases in the US and at our institution. We used a superiorly based semicircular incision, where the upper skin paddle was pulled down to the inframammary fold with the nippleareola complex pulled through the keyhole.

Results The average total reduction per breast was $584 \mathrm{~g}$, ranging from 286 to $794 \mathrm{~g}$. The inferior longitudinal pedicle was used in all the cases. The average reduction of the distance from the sternal notch to the nipple was $13 \mathrm{~cm}$ (range, $11-15 \mathrm{~cm}$ ). The mean decrease in the bra cup size was 1.7 cup sizes (range, a decrease of 1 to 3 ). We obtained very satisfactory results with a less noticeable scar, no complication such as necrosis of the nipple or the skin flap, wound infection, aseptic necrosis of the breast tissue, or wound dehiscence. One patient had a small hematoma that resolved spontaneously.

Conclusions This technique is straightforward and easy to learn, and offers a safe, effective, and predictable way for treating mammary hypertrophy.

Keywords Breast / Nipples / Mammaplasty
Correspondence: Yong Hae Lee Department of Plastic and Reconstructive Surgery, Konyang University College of Medicine, 158 Gwanjeodong-ro, Seo-gu, Daejeon 302-718, Korea Tel: $+82-42-600-9210$ Fax: +82-42-600-9251 E-mail: yonghlee2001@yahoo.com

This article was presented at the 71st Congress of the Korean Society of Plastic and Reconstructive Surgeons on November 1-3, 2013, in Seoul, Korea.

No potential conflict of interest relevant to this article was reported.

Received: 13 Dec 2014 - Revised: 7 Mar $2015 \bullet$ Accepted: 18 Apr 2015

pISSN: 2234-6163 • elSSN: 2234-6171 • http://dx.doi.org/10.5999/aps.2015.42.4.446• Arch Plast Surg 2015;42:446-452

\section{INTRODUCTION}

Reduction mammaplasty is a common procedure in plastic surgery and its use is increasing because of weight gain and aging. Reducing breast volume improves shoulder and back pain, chest discomfort, contact dermatitis, and unpleasant appearance of the body contour [1].

Because breasts are nourished by abundant blood circulation from several directions, various surgical techniques have been used for breast reduction. Many approaches, including inverted $T$ shape, periareolar incision, snowball shape incision, and vertical incision, were utilized. Further, traditional inferior and central pedicle inverted $\mathrm{T}$-shaped scar methods are very popular [2]. However, most procedures leave a prominent scar in the mid-lower breast, which is aesthetically unpleasant.

In the case of large pendulous breasts in which the nipples are located more than $40 \mathrm{~cm}$ from the sternal notch, transposition of the nipples and the mound of the breast with pedicles is con- 
strained using conventional techniques. Amputation of the breast with a free graft of the nipple was traditionally recommended in the case of large pendulous breasts [3]. However, grafted nipples ended up flat and discolored and had partial necrosis, making them aesthetically unpleasant [4].

In 1925, Passot [5] described the transposition of the nippleareolar complex into a buttonhole incision more cephalically on the breast mound, which results in no vertical scar on the reduced breast. In 2003, Lalonde et al. [6] described the no-verticalscar breast reduction that allows removal of the vertical scar portion of the inferior pedicle-wise pattern $\mathrm{T}$ scar. We referred to the Passot and Lalonde technique. We used a superiorly based semicircular flap whose upper skin paddle was pulled down to the inframammary fold and the nipple-areola complex was pulled out through the keyhole at the proper position. This approach does not leave a vertical scar in the mid breast and only one transverse scar, which is hidden within the inframammary fold. Another benefit of this procedure is that the nipples can be easily transposed to the proper position and the mount of the breast contour $[6,7]$. This article describes the reported series of horizontal breast reduction performed by a single surgeon. The authors discuss their experience here.

\section{METHODS}

Between September 1996 and October 2013, our senior author used this technique in 38 cases ( 76 breasts) in the US and at our institution. Patient characteristics were then analyzed, including, age, body mass index, ethnicity, significant weight gain, preoperative and postoperative brassiere size, preoperative and postoperative distance from the sternal notch to the nipple, several preoperative and postoperative macromastia-related symptoms (back, neck, or shoulder pain; chest discomfort; rashes and/or itching; and painful brassiere strap grooving) and postoperative complications. The weight of the excised breast tissue was measured in the operating room. Patients were generally seen at 6 weeks, 4 months, 8 months, 1 year, and 2 years. Measurements of the brassiere size and the distance from the sternal notch to the nipple were performed 4 months after surgery. Patients were then analyzed on the basis of the change in the bra cup size. The decrease in cup size, not a unit width of the breast, was used alone. For example, a change in bra size from $\mathrm{D}$ to $\mathrm{C}$ was noted as a decrease of one cup size (Table 1). We asked patients about the macromastia-related symptoms they experienced before and after surgery (at 8 months postoperatively). The patients were asked to give a subjective rating on a scale of 1 to 10 , corresponding to the symptoms (Table 2).

\section{Design}

Before surgery, with the patient in the standing position, an indelible marker is used to mark a superiorly based smooth curve lineal line as the superior pedicle, which will be pulled down to the inframammary fold. This semicircular design should aim for a proper breast mound. As a result considering the size of the chest, the width of the upper flap should measure approximately $11-12 \mathrm{~cm}$. Nipples are pulled out through the keyhole at the proper location (Fig. 1) [5]. Penn [8] proposed that the ideal distance from the sternal notch to the nipple is $21 \mathrm{~cm}$. The general consensus is that a satisfactory measurement from the sternal notch to the nipple ranges from 19 to $21 \mathrm{~cm}$, equivalent to the fourth intercostal space and the mid level of the humerus, and both the torso length and the thoracic cage dimensions must be considered when determining proper nipple location [9]. The distance from the nipples to the inframammary fold should be $5-6 \mathrm{~cm}$ (Fig. 2A); this distance is important for preventing a recurrence of the ptosis of the breast or nipples [6]. In case the upper skin paddles are not long enough in a moderate-size breast, we make a small semicircular marking on the middle of the inframammary fold, compensating for the shortness of the upper skin flap. In more detail, if the distance between the lower border of the semicircular line from the upper border of the nipple areola complex is less than $6 \mathrm{~cm}$, we design a semicircular flap with insufficient distance to the inframammary fold (Fig. 2B). For achieving a minimal areolar scar, the periareolar scar can be designed to be tension free. We do this by measuring the areola at $4.0-5.0 \mathrm{~cm}$ with the patient in the sitting position. We then draw the new areola site circle at $2.5-3.0 \mathrm{~cm}[6]$.

\section{Surgical technique}

The procedure was performed with the patient in the supine position, with arms abducted on arm boards. However, the arm should not be at a right angle, because this can distort the breast shape at the time of closure. Initially, a tumescent solution is injected into the dermal layer of the inferior pedicle, aiming for easier de-epithelialization and less bleeding during dissection. To prevent necrosis of the flap, the inferior pedicle should be 2.5 $\mathrm{cm}$ in thickness and at least $9 \mathrm{~cm}$ in width (Fig. 3). The upper skin flap is elevated between the subcutaneous tissue and scarpa's fascia reaching the upper end of the breast. The upper skin flap should be kept relatively thick in order to maintain as much superior fullness as possible. Therefore, the thickness of the upper skin flap should be at least $1.5 \mathrm{~cm}$ (Fig. 3). Upper flap elevation to the clavicle is not necessary. The breast tissue is then removed from the upper, lower medial, and lower lateral portions of the breast, leaving enough tissue in the inferior longitudinal pedicle to provide good mounting of breast size and shape (Fig. 


\section{Table 1. Patient characteristics and results}

\begin{tabular}{|c|c|c|c|c|c|c|c|c|c|}
\hline \multirow[t]{2}{*}{ Patient } & \multirow{2}{*}{ Age (yr) } & \multirow{2}{*}{ Race } & \multirow{2}{*}{$\begin{array}{c}\text { BMI } \\
\left(\mathrm{kg} / \mathrm{m}^{2}\right)\end{array}$} & \multicolumn{2}{|c|}{$\mathrm{SN}$ to NAC (cm) } & \multicolumn{2}{|c|}{ Brassiere size (cup) } & \multicolumn{2}{|c|}{$\begin{array}{l}\text { Reduction Vol per } \\
\text { breast (g) }\end{array}$} \\
\hline & & & & Preop & Postop & Preop & Postop & $\mathrm{Rt}$ & Lt \\
\hline 1 & 47 & Caucasian & 34 & 34 & 21 & $\mathrm{D}$ & C & 535 & 548 \\
\hline 2 & 44 & Caucasian & 33.9 & 35 & 21 & $\mathrm{DD}$ & C & 546 & 569 \\
\hline 3 & 64 & Caucasian & 33.6 & 38 & 22 & $\mathrm{DD}$ & C & 522 & 516 \\
\hline 4 & 45 & Black & 38.1 & 40 & 23 & DDD & D & 789 & 781 \\
\hline 5 & 53 & Caucasian & 32.8 & 32 & 21.5 & $\mathrm{D}$ & C & 455 & 451 \\
\hline 6 & 41 & Caucasian & 34.4 & 30.5 & 22 & $\mathrm{DD}$ & C & 520 & 511 \\
\hline 7 & 59 & Caucasian & 36.2 & 35 & 21.5 & $\mathrm{DD}$ & C & 571 & 588 \\
\hline 8 & 53 & Caucasian & 32.5 & 32.5 & 21 & $\mathrm{D}$ & C & 434 & 439 \\
\hline 9 & 51 & Caucasian & 33.6 & 33 & 21 & DD & C & 592 & 603 \\
\hline 10 & 41 & Caucasian & 35 & 32 & 21.5 & $\mathrm{DD}$ & C & 586 & 588 \\
\hline 11 & 43 & Caucasian & 31.2 & 31 & 21.5 & $\mathrm{D}$ & C & 421 & 429 \\
\hline 12 & 60 & Black & 35 & 39 & 22.5 & $\mathrm{DD}$ & C & 682 & 685 \\
\hline 13 & 49 & Caucasian & 31.6 & 33 & 21 & $\mathrm{D}$ & C & 496 & 513 \\
\hline 14 & 45 & Caucasian & 35.8 & 35 & 22 & $\mathrm{DD}$ & C & 574 & 559 \\
\hline 15 & 52 & Caucasian & 34.3 & 35 & 21.5 & $\mathrm{DD}$ & C & 572 & 584 \\
\hline 16 & 50 & Caucasian & 37.2 & 38.5 & 22 & DDD & D & 682 & 698 \\
\hline 17 & 42 & Caucasian & 31.6 & 31.5 & 21 & $\mathrm{DD}$ & C & 560 & 572 \\
\hline 18 & 47 & Caucasian & 38.4 & 41 & 22.5 & DDD & D & 751 & 733 \\
\hline 19 & 55 & Caucasian & 36.2 & 36 & 22 & $\mathrm{DD}$ & C & 542 & 530 \\
\hline 20 & 43 & Caucasian & 34.2 & 32 & 21 & DD & C & 551 & 531 \\
\hline 21 & 46 & Caucasian & 36.8 & 37 & 21.5 & DDD & C & 705 & 711 \\
\hline 22 & 45 & Caucasian & 38.5 & 35.5 & 21.5 & $\mathrm{DD}$ & C & 656 & 671 \\
\hline 23 & 44 & Caucasian & 32.4 & 30.5 & 21 & $\mathrm{D}$ & C & 428 & 436 \\
\hline 24 & 62 & Caucasian & 34.2 & 40 & 22 & DDD & D & 793 & 762 \\
\hline 25 & 51 & Caucasian & 34.7 & 34 & 21.5 & $\mathrm{DD}$ & C & 567 & 559 \\
\hline 26 & 48 & Caucasian & 33.6 & 32 & 21 & $\mathrm{D}$ & C & 578 & 601 \\
\hline 27 & 67 & Caucasian & 35.1 & 42 & 24 & DDD & D & 789 & 794 \\
\hline 28 & 45 & Black & 37.2 & 38 & 22.5 & $\mathrm{DD}$ & C & 572 & 578 \\
\hline 29 & 42 & Caucasian & 31. & 34 & 21 & $\mathrm{D}$ & C & 514 & 507 \\
\hline 30 & 48 & Black & 32.9 & 33.5 & 21.5 & D & C & 466 & 442 \\
\hline 31 & 51 & Caucasian & 33.2 & 35 & 22 & $\mathrm{DD}$ & C & 571 & 592 \\
\hline 32 & 44 & Caucasian & 36.9 & 33 & 21.5 & DDD & C & 699 & 704 \\
\hline 33 & 58 & Caucasian & 35.7 & 33 & 22 & $\mathrm{DD}$ & D & 582 & 585 \\
\hline 34 & 43 & Caucasian & 32.4 & 31.5 & 21 & $\mathrm{D}$ & C & 506 & 519 \\
\hline 35 & 45 & Caucasian & 31.2 & 31 & 21 & $\mathrm{D}$ & C & 475 & 472 \\
\hline 36 & 53 & Caucasian & 35.4 & 36 & 22.5 & $\mathrm{DD}$ & D & 559 & 574 \\
\hline 37 & 43 & Asian & 30.1 & 31 & 21.5 & $\mathrm{D}$ & C & 309 & 313 \\
\hline 38 & 52 & Asian & 31.5 & 30.5 & 21 & D & C & 286 & 301 \\
\hline
\end{tabular}

BMI, body mass index; SN to NAC, mean distance from sternal notch to nipple for both breasts; Preop, preoperatively; Postop, postoperatively; Vol, volume; Rt, right; Lt, left.

\section{Table 2. Complication}

\begin{tabular}{|lc|}
\hline Complication & No. of patients \\
\hline Necrosis of nipple or skin flap & 0 \\
Wound infection & 0 \\
Sensory change & 0 \\
Aseptic necrosis of breast tissue & 0 \\
Dehiscence of wound & 0 \\
Hematoma & 1 \\
Seroma & 0 \\
\hline
\end{tabular}

4A, B). A majority of the breast tissue is removed from the lateral segment. The redundant breast tissue is located laterally, par- ticularly in the excessively large pendulous breast. There should not be too much lateral traction while holding the lateral segment to prevent excessive undermining of the inferior pedicle. After excision of the breast tissue, the upper flap is pulled gently to the inframammary line and sutured. The length of the upper flap can be modified with the creation of a small semicircular flap in the lower end of the middle inframammary fold in the case of insufficient length of the upper skin flap.

At the new location of the nipple, circular markings are made, which are smaller than the actual size of the nipple because holes for the nipple-areola complex are stretched out and become larger. Through the hole, the nipple is delivered and sutured with 


\section{Fig. 1. Preoperative design}

Superiorly based semicircular line: medial end of the inframammary fold to lateral end of the inframammary fold. Nipple position, distance between the midclavicular line and the new nipple-areola complex: 19-21 cm.

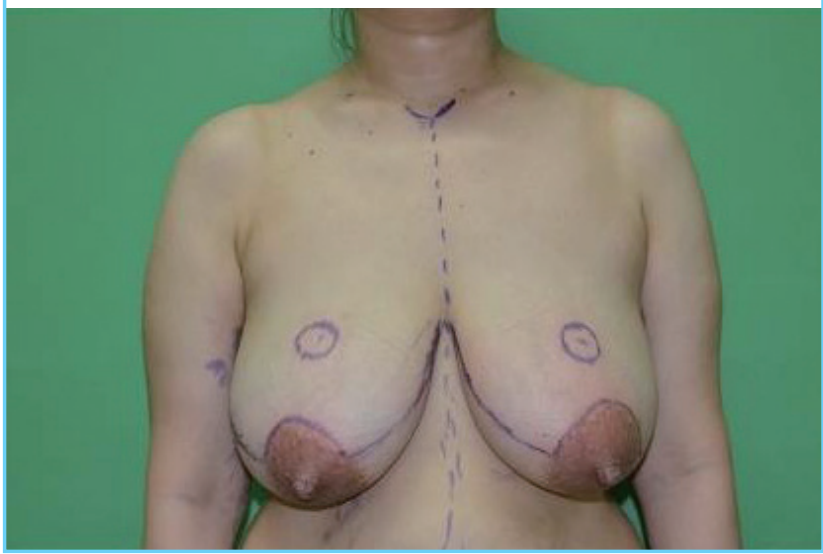

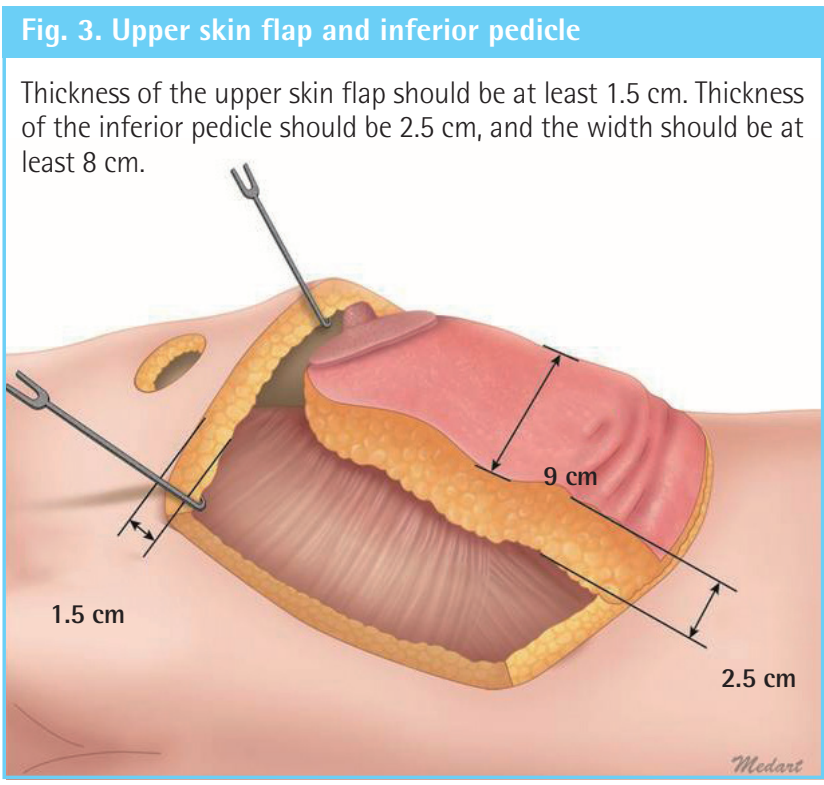

\section{Fig. 2. Preoperative design}

(A) New location of the nipple: a circular margin is made which is smaller than the nipple. (B) Distance between the lower end of the semicircular line to the nipple-areola complex $(a+b): 5-6 \mathrm{~cm}$.
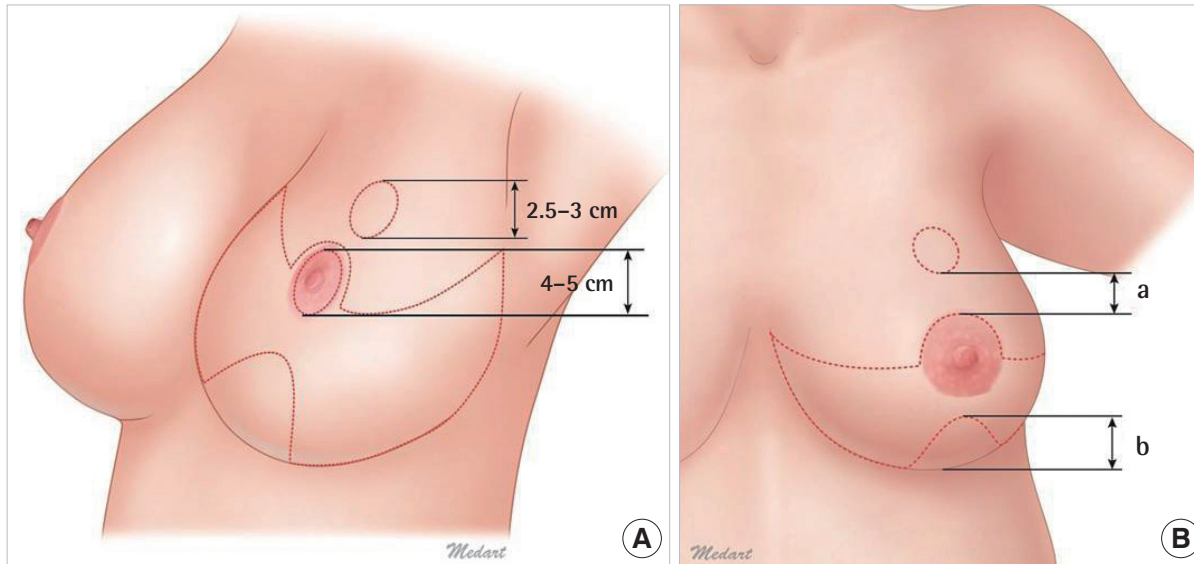

\section{Fig. 4. Intraoperative view}

Operative technique for semicircular horizontal reduction mammaplasty using inferior dermoglandular pedicle for transposition of the nippleareola complex. (A) Excision of en bloc is performed. The inferior dermoglandular pedicle is $2.5 \mathrm{~cm}$ thick. (B) Outline of the two segments to be resected the medial and lateral; yellow and dotted line: superior segment to be resected below the skin flap. (C) Closure of the breast.
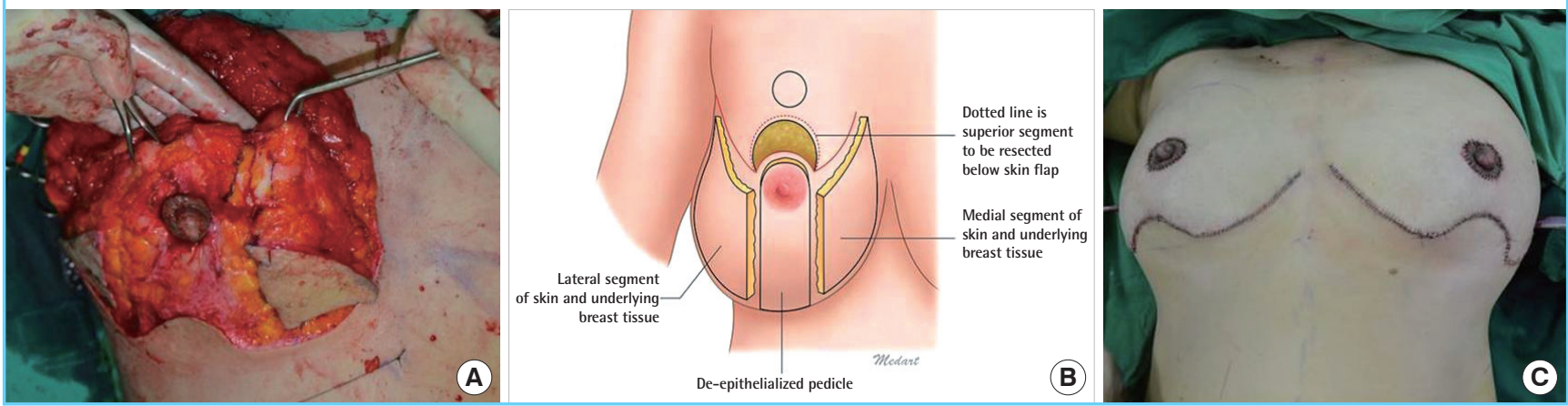

minimal tension. The nipples should be located $19-21 \mathrm{~cm}$ from the sternal notch or the midclavicular line and 9-11 cm from the midline on symmetrical locations. The inframammary fold incision is closed, and a drain is placed in each breast (Fig. 4C). 


\section{Fig. 5. Preoperative and postoperative view}

(A-C) A patient (Table 1, patient 37) with large pendulous breasts has a lower location of the nipple-areola complex. The distance from the sternal notch to the nipple is $31 \mathrm{~cm}$. (D-F) Four months after surgery. The distance from the sternal notch to the nipple is $21.5 \mathrm{~cm}$. The patient has maintained a good contour with minimal bottoming out. Further, the scars around the areola are excellent.
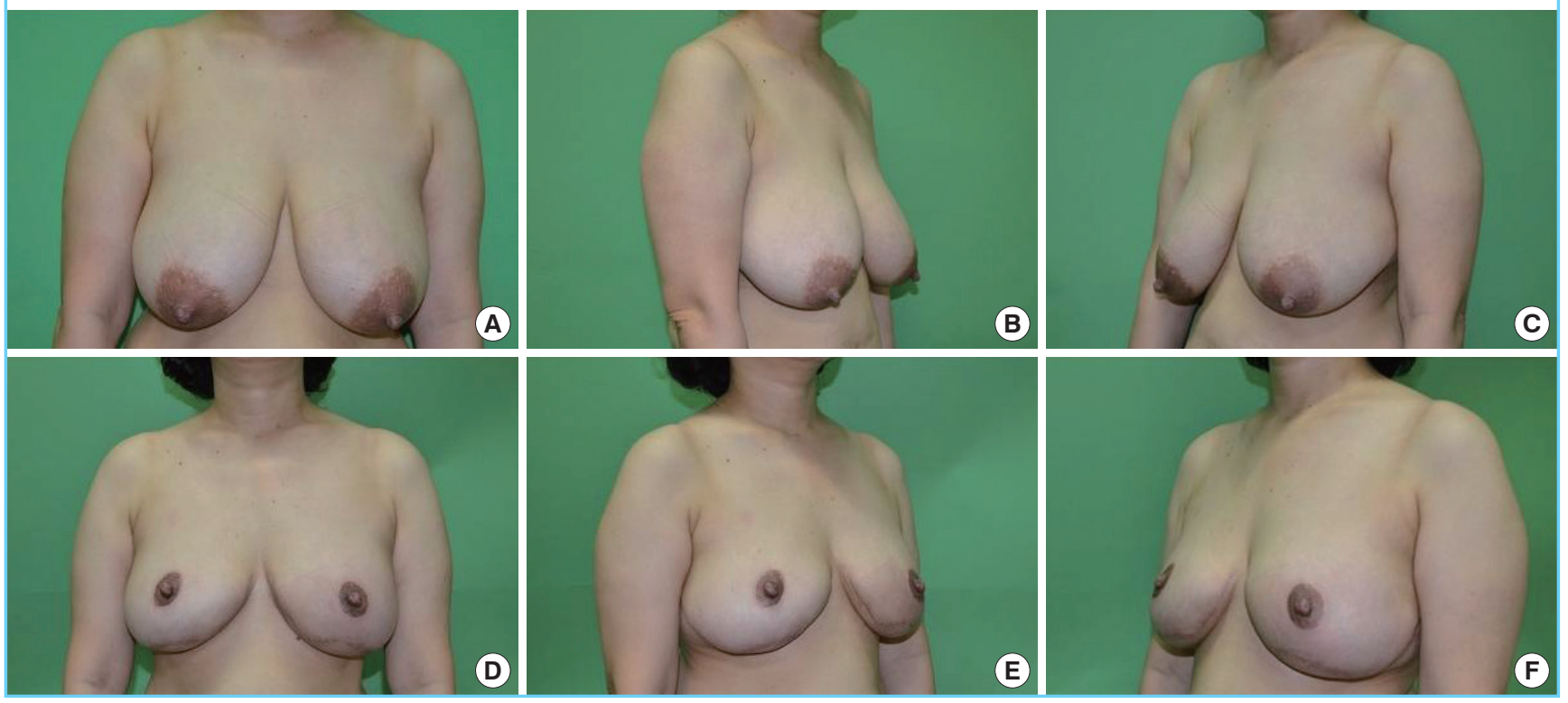

\section{RESULTS}

The average age of the patients was 49.2 years (range, $41-67$ years). The average body mass index was $34.3 \mathrm{~kg} / \mathrm{m}^{2}$ (range, $\left.30.1-38.5 \mathrm{~kg} / \mathrm{m}^{2}\right)$. The average total reduction per breast was $584 \mathrm{~g}$, ranging from 286 to $794 \mathrm{~g}$. The inferior longitudinal pedicle was used in all cases. The average specimen weight was 564 $\mathrm{g}$ (range, 286-793 g) for the right breast and $567 \mathrm{~g}$ (range, 301$794 \mathrm{~g}$ ) for the left breast. The average follow-up period was 18 months (range, $0.3-2$ years). Preoperatively, the average distance from the sternal notch to the nipple was $34.6 \mathrm{~cm}$ (range, 30.5$42 \mathrm{~cm}$ ) for both breasts. Postoperatively, the average distance from the sternal notch to the nipple was $21.6 \mathrm{~cm}$ (range, 21-24 $\mathrm{cm}$ ) for both breasts. The average reduction of the distance from the sternal notch to the nipple was $13 \mathrm{~cm}$ (range, $11-15 \mathrm{~cm}$ ). Preoperatively, the median bra size was a DD cup. Postoperatively, the median bra size was a $\mathrm{C}$ cup. Patients reported a mean decrease in bra cup size of 1.7 cup sizes (range, decrease of 1 to 3). During follow-up, there were no patients with significant weight gain (Table 1).

The effect of reduction mammaplasty on several macromastiarelated symptoms was assessed. The semicircular horizontal reduction mammaplasty resulted in significant decreases in all macromastia-related symptoms analyzed, including back pain (preoperatively vs. postoperatively, 5.5 vs. 1.2$)$, neck pain ( 5.8 vs. 1.2 ), shoulder pain (3.8 vs. 1.3 ), chest discomfort (6.8 vs. 1.1), rashes and/or itching (3.2 vs. 1.5 ), and painful brassiere

\section{Table 3. Macromastia associated symptoms}

\begin{tabular}{|lccc|}
\hline Characteristic & $\begin{array}{c}\text { Preoperatively } \\
\text { (range) }\end{array}$ & $\begin{array}{c}\text { Postoperatively } \\
\text { (range) }\end{array}$ & $\begin{array}{c}\text { Pain relief } \\
\text { rate }\end{array}$ \\
\hline Back & $5.5(4-7)$ & $1.2(0-2)$ & 2.5 \\
Neck & $5.8(3-7)$ & $1.2(0-3)$ & 2.7 \\
Shoulder & $6.2(4-7)$ & $1.3(0-2)$ & 2.9 \\
Discomfort of the chest & $6.8(4-7)$ & $1.1(0-3)$ & 3.4 \\
Rash and/or itching & $3.2(4-7)$ & $1.5(0-2)$ & 1 \\
Painful brassiere strap & $5.3(4-7)$ & $1.4(0-2)$ & 2.3 \\
$\quad$ grooving & & & \\
\hline
\end{tabular}

Pain relief rate, decrease pain score per a breast cup size reduction.

strap grooving (5.3 vs. 1.4). We have tried to quantify the symptoms according to the breast cup size reduction (decrease pain score per breast cup size reduction). As a result, the back pain score was 2.5 , neck pain score was 2.7 , shoulder pain score was 2.9, chest discomfort score was 3.4, rash and/or itching score was 1 , and painful brassiere strap grooving score was 2.3 per breast cup size reduction (Table 2).

We obtained a very satisfactory outcome with the least noticeable scar (Fig. 5). No complication was observed, such as necrosis of the nipple or skin flap, wound infection, sensory change, aseptic necrosis of breast tissue, or wound dehiscence. One patient had a small hematoma that resolved spontaneously (Table 3).

\section{DISCUSSION}

As our data unequivocally demonstrate, semicircular horizontal 
reduction mammaplasty provides significant improvement for patients with respect to macromastia-related symptoms. Chest discomfort resulted in the most dramatic decrease. These findings are consistent with those of several prior studies that have analyzed the effect of reduction mammaplasty on patient wellbeing. Although several authors have reported their experience with horizontal reduction mammaplasty, our study mostly focused on patient outcomes $[6,7]$. We have quantified the symptoms according to the breast cup size reduction. If the data are accumulated on an ongoing basis, it will provide useful information in the field of breast reduction.

Fewer complications occurred with this technique than described in previous articles. The fact that necrosis of the nipple-areola complex never occurred in 38 cases is related to pedicle choice and design. The lateral thoracic artery, thoraco-acromial artery, internal mammary artery, and intercostal arteries that supply blood from anterior and posterior directions are the dominant arteries providing blood circulation to the breast $[10,11]$. Preserving the routes of this circulation is important for proper wound healing and preventing necrosis of the skin flap and aseptic necrosis of breast tissue. Reserving all dominant blood circulation reduces the risk of skin flap necrosis and nipple areolar necrosis $[6,7]$.

We did not experience a sensation change. Sensory innervation of the breast has three major nerve distributions, namely anterior lateral intercostals, medial intercostals, and the cervical plexus. Branches of the cervical plexus provide superior medial sensory innervation. These fibers course superficially in the subcutaneous tissue and are usually undisturbed by the surgical elevation of the upper breast skin flap. Intercostal segmental nerves contribute the remainder of the breast sensation and can be considered the primary sensory nerves [12]. The upper skin flap is elevated between the subcutaneous tissue and scarpa's fascia. Therefore, the subdermal plexus can be preserved.

Blood loss is decreased with this technique. The use of an infiltration solution containing epinephrine, an excision en bloc of breast tissue, and thorough cautery of all bleeding vessels contribute to hemostasis. No patient has ever required a blood transfusion.

It is recognized that the excessive skin undermining of vertical reduction mammaplasty leads to delayed healing [13]. Delayed wound healing did not occur in the cases considered in our study because skin undermining was avoided, and when the excision deep into the skin, minimal dissection of breast tissue was carried out laterally and superiorly; the upper skin flaps were maintained to be at least $1.5 \mathrm{~cm}$ thick throughout their length, and it was ensured that the inferior pedicle did not have too much lateral traction while the lateral segment was held.
Ideally, this surgical technique has been utilized in reduction mammaplasty to obtain proper breast shape and size, and an acceptable scar on large breasts, particularly when the nipple is located more than $40 \mathrm{~cm}$ from the sternal notch and more than 20 $\mathrm{cm}$ of transposition of the nipples is required. The conventional transverse bi-pedicle, longitudinal pedicle flap, upper lateral pedicle, transposition of the nipple, and mounting of breast method are technically contraindicated [14]. In the past, amputation of the large pendulous breast with a free nipple graft was utilized in reduction mammaplasty $[3,15]$. Gradinger [4] reported achieving satisfactory results by using nipple-areola transplantation. However, in our experience, amputation of the breast with a free nipple graft does not yield an aesthetically pleasing shape of the breast and shape of nipples because of flat deformation, discoloration, and partial necrosis of the nipple-areola complex. In the initial phase of this study, a patient presented with gigantomastia. Instead of amputating the breast, the semicircular horizontal technique of the skin with a smooth, semicircular incision in the upper skin flap was designed.

This technique can be applied to breasts of moderate size as well as large pendulous breasts by adjusting the design, thereby avoiding amputation. Perhaps, the most important advantage of the semicircular horizontal technique, particularly from the patient's perspective, is the elimination of the longitudinal scar in the center of the breast, which is the most noticeable. This technique does not involve the use of complicated, multiple flap rotations; thus, the final scars include the scar around the nippleareola complex and at the inframammary sulcus only. A transverse scar can be hidden within the inframammary fold and is less visible without a vertical scar on the midline [6]. The surgical procedure is very simple in terms of flap design and dissection [6]. Our technique requires a shorter operating time than other techniques. We were able to shorten the operating time by 30-40 minutes as compared to other conventional vertical techniques [16].

The horizontal breast reduction can result in a boxy shape of the breast and tends to show a decrease in the projection of the breast mound $[17,18]$. For the improvement of projection and shape, a proper amount of tissue should be reserved in the inferior central flap and a significant amount of the breast tissue attached to the upper skin flap. This leaves a significant amount of breast tissue in the upper skin flap, which has several benefits. It can minimize the flatness of the upper breast and can reduce the mechanical force on the lower breast. This reduces the secondary bottoming out. Elevation of the upper flap to the clavicle is not necessary. Excessive dissection can lead to the problem of blood flow and the upper flap can drop over time. Further, for proper mounting of the breast, the width or semicircular line 
should be designed properly. If the semicircular line is too flat, the breast mound becomes flat and boxy. We adjust the width of the upper flap by approximately $11-12 \mathrm{~cm}$ considering the chest size. The width of the breast can be adjusted through the lateral and medial resections of the upper breast tissue. However, our method is more effective when the distance from the nipple to the sternal notch is $28-33 \mathrm{~cm}$.

In 2003, Lalonde et al. [6] published a horizontal reduction mammaplasty technique similar to our technique. However, there are some differences between these two techniques in that the semicircular line is more concave and the width adjustment is possible by using lateral and medial resection of the upper breast.

We obtained acceptable breast reduction results by using this technique. The semicircular horizontal mammaplasty is easy to design, can be modified according to breast size and shape, and has consistently produced good breast shape. A semicircular scar can be hidden in the inframammary fold and is less visible without a vertical scar on the midline. This technique is straightforward and easy to learn, and offers a safe, effective, and predictable way to treat moderately sized and large pendulous breasts.

\section{REFERENCES}

1. Kalliainen LK; ASPS Health Policy Committee. ASPS clinical practice guideline summary on reduction mammaplasty. Plast Reconstr Surg 2012;130:785-9.

2. Hidalgo DA, Elliot LF, Palumbo S, et al. Current trends in breast reduction. Plast Reconstr Surg 1999;104:806-15.

3. Mathes SJ. Plastic surgery. Vol. 6. Philadelphia: Saunders Elsevier; 2006.

4. Gradinger GP. Reduction mammoplasty utilizing nipple-areola transplantation. Clin Plast Surg 1988;15:641-54.

5. Passot R. La correction esthetique du prolapsus mammaire par le procede de la transposition du mamelon. Presse Med 1925;33:317-8.
6. Lalonde DH, Lalonde J, French R. The no vertical scar breast reduction: a minor variation that allows to remove vertical scar portion of the inferior pedicle wise pattern $\mathrm{T}$ scar. Aesthetic Plast Surg 2003;27:335-44.

7. White CP, Hynes NM. The horizontal breast reduction: surgical tips for maintaining projection. Can J Plast Surg 2013; 21:167-72.

8. Penn J. Breast reduction. Br J Plast Surg 1955;7:357-71.

9. Westreich M. Anthropomorphic breast measurement: protocol and results in 50 women with aesthetically perfect breasts and clinical application. Plast Reconstr Surg 1997;100:46879.

10. Maliniac JW. Arterial blood supply of the breast. Arch Surg 1943;47:329-43.

11. Palmer JH, Taylor GI. The vascular territories of the anterior chest wall. Br J Plast Surg 1986;39:287-99.

12. Neligan P. Plastic surgery. Vol. 5. London; New York: Elsevier Saunders; 2013.

13. Berthe JV, Massaut J, Greuse M, et al. The vertical mammaplasty: a reappraisal of the technique and its complications. Plast Reconstr Surg 2003;111:2192-9.

14. Hidalgo DA. Vertical mammaplasty. Plast Reconstr Surg 2005;115:1179-97.

15. Janis JE. Essentials of plastic surgery. St. Louis: Quality Medical Pub.; 2007.

16. Hall-Findlay EJ. A simplified vertical reduction mammaplasty: shortening the learning curve. Plast Reconstr Surg 1999; 104:748-59.

17. Movassaghi K, Liao EC, Ting V, et al. Eliminating the vertical scar in breast reduction-Boston modification of the Robertson technique. Aesthet Surg J 2006;26:687-96.

18. Lalonde DH, French R, Lalonde J. The no vertical scar breast reduction: how to delete the vertical scar of the standard Tscar breast reduction and produce an excellent breast shape. Perspect Plast Surg 2001;15:103-18. 